\title{
Invasive Ductal and Invasive Lobular Breast Carcinoma
}

National Cancer Institute

\section{Source}

National Cancer Institute. Invasive Ductal and Invasive Lobular Breast Carcinoma. NCI

Thesaurus. Code C6393.

An invasive ductal breast carcinoma associated with an invasive lobular carcinomatous component. 